\title{
ARTIGO
}

dol https://doi.org/10.22481/rpe.v16i43.6990

\section{CONTRIBUIÇÕES DO PROGRAMA RESIDÊNCIA PEDAGÓGICA PARA A FORMAÇÃO DE PROFESSORES DE GEOGRAFIA}

\author{
CONTRIBUTIONS OF EDUCATIONAL RESIDENCY PROGRAM TO GEOGRAPHY'S \\ TEACHERS FORMATION
}

\section{CONTRIBUCIONES DEL PROGRAMA DE FORMACIÓN DEL PROFESORADO DE GEOGRAFÍA}

Vilmar José Borges

Universidade Federal do Espírito Santo - Brasil

Lucas de Souza Leite

Universidade Federal do Espírito Santo - Brasil

Marcone Henrique de Freitas

Universidade Federal do Espírito Santo - Brasil

\begin{abstract}
Resumo: O presente estudo se propôs a desenvolver e socializar reflexões acerca das potencialidades do Programa Residência Pedagógica (PRP) para a formação docente, tomando como base a experiência do subprojeto de Geografia da Universidade Federal do Espírito Santo (UFES). Para tanto, utilizou-se como caminho teórico-metodológico os aportes da história oral (BOM MEIHY, 1996), realizando entrevistas com residentes pedagógicos e professores/as preceptores/as, com foco em suas percepções, seus saberes e seus fazeres acerca da contribuição do Programa para a formação de professores/as de Geografia. Como resultado, observou-se que o PRP configura-se como uma oportunidade de complementar a experiência dos Estágios Obrigatórios, possibilitando uma série de vivências que provavelmente os/as licenciando/as só teriam exercendo a docência, além de contribuir com a formação continuada dos/as professores/as preceptores/as.
\end{abstract}

Palavras-chave: Formação Docente. Geografia. Programa Residência Pedagógica.

Abstract: The present study proposed to develop e socialize reflections about the potentialities of Educational Residency Program (PRP) for teachers training, based on the experiences of Geography Subproject at Federal University of Espírito Santo (UFES). For this purpose, the theoretical and methodological resource of Oral History (BOM MEIHY, 1996) was used, performing interviews with Residencial Students and Preceptors Professors, focused on their perceptions, their knowledge and practices about the contributions of the Program to geography teachers formation. As results, we concluded that the Program appears as an opportunity to complement the experience of mandatory 
internship, allowing a lot of experiences that probably the undergraduate students would have only being professors, furthermore contributing to continuous education of the Preceptors Professors.

Keywords: Educational Residency Program. Teachers Training. Geography.

Resumen: Este estudio tuvo como objetivo desarrollar y socializar reflexiones sobre el potencial del Programa de Residencia Pedagógica (PRP) para la formación docentes, basado en la experiencia del subproyecto de Geografía en la Universidad Federal de Espírito Santo (UFES). Por esta razón, las contribuciones de la Historia Oral se utilizaron como un enfoque teórico-metodológico (BOM MEIHY, 1996), realizando entrevistas con residentes pedagógicos y maestros/preceptores, centrándose en sus percepciones, conocimientos y acciones sobre la contribución. del programa de formación del profesorado de Geografía. Como resultado, se observó que el PRP está configurado como una oportunidad para complementar la experiencia de pasantías obligatorias, permitiendo una serie de experiencias que los graduados probablemente solo enseñaría, además de contribuir a la capacitación continua de los estudiantes/profesores/preceptores.

Palabras clave: Formación Docente. Geografía. Programa de Residencia Pedagógica.

\section{Considerações Iniciais}

O presente artigo socializa reflexões acerca de contribuições do subprojeto Geografia do Programa Residência Pedagógica (PRP) ${ }^{1}$, implementado no período 2018/2019, na Universidade Federal do Espírito Santo (UFES), com foco nos seus impactos na formação docente, explícitas nas vozes de professores/as preceptores/as e residentes bolsistas diretamente envolvidos. O programa, lançado pelo Governo Federal no início de 2018, se fundamenta nas Portarias/CAPES 35 e 45/2018 e no edital/CAPES 06/2018, ao qual é caracterizado por conceder bolsas de estudos aos estudantes das licenciaturas, visando o desenvolvimento de atividades de iniciação à docência e implementando práticas de formação docente.

A possibilidade de se estabelecer práticas de formação docente para além das horas de Estágio Curricular Supervisionado, previstas na Lei de Diretrizes e Bases da Educação (LDB) - Lei 9394/96 - é atualmente, regulamentada pela Resolução CNE/CP 02/2015 (BRASIL, 1996) que "Define as Diretrizes Curriculares Nacionais para a formação inicial em nível superior (cursos de licenciatura, cursos de formação pedagógica para graduados/as e cursos de segunda licenciatura) e para a formação continuada” (BRASIL, 2015). Essa prática foi

\footnotetext{
${ }^{1}$ O Programa Residência Pedagógica (PRP) é uma ação que objetiva apoiar Instituições de Ensino Superior (IES) na execução de projetos capazes de articular teoria e prática no âmbito dos cursos de licenciatura, implementados em parceria com as redes públicas de educação básica (BRASIL, 2018).
} 
inicialmente instituída com o Decreto n. ${ }^{\circ}$ 6.755/2009 (BRASIL, 2009), que embora revogado, abriu possibilidades para as Instituições de Ensino Superior (IES) organizarem, sob regime de colaboração, programas de iniciação à docência com escolas de educação básica, tais como o Programa Institucional de Bolsa de Iniciação à Docência (PIBID) e, também, como o PRP, aqui tomado como foco de análise.

A proposta de desenvolvimento do PRP foi realizada pela colaboração e parceria entre a Coordenação de Aperfeiçoamento de Pessoal de Nível Superior (Capes) do Ministério da Educação (MEC), os estados, o Distrito Federal e os municípios, por meio de suas secretarias de educação ou órgãos equivalentes, e as IES, que mantêm cursos de formação docente.

Neste contexto, o presente artigo tem como objetivo desvelar e problematizar as contribuições que o PRP trouxe para o ensino e formação inicial de docentes em Geografia da UFES, explícitas nas vozes, saberes e fazeres dos professores/as preceptores/as e licenciandos/as residentes diretamente envolvidos com o subprojeto Geografia.

A pesquisa está estruturada de modo que, num primeiro momento, é realizada uma contextualização da institucionalização do programa, num segundo momento, apresenta-se a perspectiva dos professores preceptores acerca do mesmo e, finalmente, a visão dos residentes pedagógicos. Além disso, compartilhamos algumas metodologias exitosas realizadas nas escolas-campo durante a vigência do programa.

Ao se inscrever no Programa Residência Pedagógica, o subprojeto Geografia/UFES visou proporcionar vivências e experiências com o cotidiano escolar e o exercício da docência na educação básica. Assim, decorridos dezoito meses de sua implementação e concluídos os prazos previstos no edital de sua convocação, bem como a possibilidade de chamada de novos subprojetos, justifica-se a realização de uma investigação, buscando nas vozes, saberes e fazeres dos sujeitos diretamente envolvidos (licenciandos/as, residentes e professores/as preceptores/as), subsídios que possam contribuir para desenvolver e socializar reflexões acerca das potencialidades do Programa no enriquecimento da formação inicial e continuada de professores de Geografia.

Nesta esteira, destaca-se que o Programa buscou contribuir para a formação de ambientes propícios ao processo de aprendizagem e socialização profissional que, segundo Nóvoa (2019), é uma necessidade essencial. De acordo com esse autor, o atual ambiente das universidades (formação inicial), da pesquisa (a indução profissional) e da escola (o trabalho docente) não é totalmente favorável ao desenvolvimento profissional de professores/as (NÓVOA, 2019 p. 201-02). Isto posto, o Programa Residência Pedagógica se apresenta como 
uma maneira de auxiliar na formação, indução e no trabalho docente, isto é, o período ideal de iniciação e de introdução na profissão, buscando permitir a pesquisa diretamente a partir da práxis docente.

No que concerne à práxis docente e ao par teoria-prática, observa-se implicitamente nas atuais determinações legais no âmbito dos cursos de formação (Pareceres $\mathrm{CNE} / \mathrm{CP}$ 009/2001; 21/2001; 27/2001 e 28/2001 e Resoluções CNE/CP 01 e 02/2002), uma tentativa de romper com a visão dicotômica, pautada nos moldes da ciência moderna, de que uma é mais importante que a outra, conforme salienta Pimenta (2010). Nas palavras da autora,

Teoria e prática são componentes indissociáveis da práxis, definida, conforme Vásquez (1968: 241), [...] como atividade teórico-prática, ou seja, tem um lado ideal, teórico, e um lado material, propriamente prático, com a particularidade de que, só artificialmente, por um processo de abstração, podemos separar, isolar um do outro (PIMENTA, 2010, p. 67).

Superar a dicotomia já tão enraizada, conforme demonstrado por Vásquez (1977) e comentada por Pimenta (2010), contribui para o fortalecimento da ideia de que os cursos de formação, no âmbito da graduação, precisam assumir essa responsabilidade para erradicar essa bipolaridade que também se encontra sedimentada, histórica e epistemologicamente nos currículos. Neste sentido, conforme destaca Borges (2012), “os saberes práticos não devem ser entendidos como componentes de dois âmbitos do ensino, mas vistos como único fenômeno no processo de ensinar e, por decorrência, no processo de aprender" (BORGES, 2012, p. 27).

Ademais, consideramos que o Programa emerge num contexto de possibilidades para a superação de três silêncios identificados por Nóvoa (2019) que têm marcado o período de indução profissional docente. Segundo o referido autor, são eles:

O silêncio das instituições universitárias de formação de professores, que pouca atenção têm dedicado a este período, considerando que o seu trabalho fica concluído com a entrega do diploma de conclusão do curso de licenciatura; - o silêncio das políticas educativas, que não têm conseguido definir os necessários processos de escolha dos candidatos ao magistério, de acesso à profissão e de acompanhamento dos jovens professores nas escolas; o silêncio da própria profissão docente, isto é, dos professores em exercício, mais experientes, e que deveriam assumir um maior compromisso com a formação dos seus jovens colegas. (NÓVOA, 2019, p. 200-201).

Diante do contexto delineado e na perseguição dos objetivos de desvelar, pelas vozes de sujeitos diretamente envolvidos, os impactos e contribuições do Programa Residência Pedagógica para a formação inicial e continuada, e, consequentemente, para a atuação 
docente, buscamos sustentação metodológica na abordagem da história oral (BOM MEIHY, 1996), por se apresentar como

[...] um recurso moderno usado para a elaboração de documentos, arquivamento e estudos referentes à vida social de pessoas. Ela é sempre uma história do tempo presente e também conhecida por história viva. [...] a história oral se apresenta como forma de captação de experiências de pessoas dispostas a falar sobre aspectos de sua vida mantendo um compromisso com o contexto social. (BOM MEIHY, 1996, p.13).

Bom Meihy (1996) salienta que existem três modalidades ou tendências principais nas pesquisas que se utilizam desse caminho teórico-metodológico, sendo elas: a história oral de vida, a história oral temática e a tradição oral.

$\mathrm{Na}$ história oral de vida o/a sujeito/a depoente possui maior liberdade e autonomia para dissertar sobre a sua experiência pessoal. Já na modalidade da tradição oral, o depoente sempre leva em consideração o ponto de vista coletivo remetendo às questões do passado, que geralmente se manifestam pelo que chamamos de folclore e pela transmissão de geração para geração. Na modalidade da história oral temática, existe maior objetividade, de modo que, a partir de um determinado assunto, busca-se captar a opinião do/a entrevistado/a. Neste sentido, Ichikawa e Santos (2003) enfatizam que, diferentemente da primeira modalidade, nesta ultima, aspectos pessoais só interessam se tiverem relação com a temática central.

Desta forma, nossa opção pela abordagem da história oral temática se deu justamente pelo seu caráter específico, possibilitando o direcionamento das entrevistas, seguindo um roteiro semiestruturado, de forma a desvelar a opinião, os fazeres e os saberes produzidos por estudantes da licenciatura em geografia, participantes do Programa Residência Pedagógica, bem como por Professores/as Preceptores/as, acerca das contribuições do Programa para a formação e para a atuação de professores/as de Geografia.

Após a definição da abordagem metodológica da pesquisa, bem como delimitados nossos sujeitos colaboradores (licenciandos/as residentes e professores/as preceptores/as atuantes no subprojeto Geografia-UFES), foram agendadas e realizadas as entrevistas que após transcritas e contextualizadas subsidiaram nossas reflexões.

É importante destacar que todos/as os/as sujeitos contatados concordaram com a participação na pesquisa, concedendo as respectivas entrevistas ${ }^{2}$, concordando, também, com

\footnotetext{
2 Seguindo os pressupostos e orientações metodológicas de pesquisas que se utilizam da história oral, destacamos que após transcritas e textualizadas as entrevistas, elas foram devolvidas aos/às entrevistados que as leram e cederam o uso das respectivas narrativas, inclusive, autorizando sua identificação. As cartas de cessão estão em poder dos pesquisadores.
} 
a sua identificação, não sendo, portanto, necessário recorrermos aos critérios de invisibilidade dos mesmos.

As vozes de nossos sujeitos trazem à baila narrativas prenhes de sinais e pistas dos/as licenciandos/as residentes e, também, dos/as Professores/as Preceptores/as acerca de suas perspectivas, seus saberes e seus fazeres decorrentes da implementação do subprojeto Geografia do PRP da UFES ${ }^{3}$, emergidas durante as entrevistas que foram realizadas seguindo os parâmetros e pressupostos teórico-metodológicos da história oral temática.

Tal abordagem possibilitou o registro e a reflexão das narrativas de sujeitos diretamente envolvidos no processo e dos movimentos que acontecem no cotidiano das escolas-campo, caracterizando-se como subsídios para as nossas reflexões. Ademais, configuram-se como fonte de saberes teórico-metodológicos relacionados ao ensinaraprender ${ }^{4}$ Geografia.

\section{O Programa Residência Pedagógica (PRP) na visão dos/as professores/as preceptores}

No intuito de estimular memórias e narrativas que desvelassem as percepções dos professores/as preceptores/as, utilizamos como questões basilares para as entrevistas um roteiro semiestruturado com as seguintes indagações: "Qual a importância do Programa na formação de novos/as docentes?"; "O PRP, de alguma maneira, contribuiu com a sua formação continuada e atuação docente?" e "De que maneira a presença e atuação do/a residente contribuiu para o ensino de geografia na escola-campo em que atua?".

Com referência à importância do programa para a formação de novos docentes, notase uma linearidade de pensamentos que é caracterizada pela particularidade do PRP em possibilitar a iniciação da prática docente por parte dos Residentes. Assim, a partir do exercício prático os/as residentes, agora inseridos no cotidiano escolar, passam a construir paulatinamente a prática docente, autonomia e confiança a partir do exemplo de um/a profissional graduado/a e experiente que são possibilitadas por meio da observação e troca de saberes. Nesta seara, destaca-se a narrativa de uma das professoras preceptoras sobre o Programa. Segundo ela,

\footnotetext{
${ }^{3} \mathrm{O}$ subprojeto de Geografia recebeu o número 3008

${ }^{4}$ Utiliza-se o termo ensinaraprender conforme Freire (1997), partindo do pressuposto de que quem ensina aprende ao ensinar e quem aprende ensina ao aprender.
} 
[...] O Programa contribui muito para a formação dos licenciandos, buscando essa aproximação do acadêmico com a prática. Da universidade com a educação básica. Muitas vezes a gente percebe que essa relação ainda é muito distante, e eu sempre falo com eles (residentes) que a gente só aprende a ser professor sendo professor [...] [sic] (RICARDO, 2019).

Corroborando esta percepção de que a aproximação permitida pelo PRP entre o ensino acadêmico e a educação básica é enriquecedora para a formação de novos professores, outro professor preceptor destaca:

O programa contribui com questões formativas, quando você junta a teoria com prática. Uma coisa é você entender a questão das aulas de climatologia, da dinâmica da natureza, de forma teórica, outra é de como você irá passar isso, como você vai colocar isso em diferentes turmas com diferentes segmentos. Então, essa possibilidade é rica para o professor, é rica para o aluno e é rica para o licenciado [sic] (NASCIMENTO, 2019).

As narrativas dos preceptores/as entrevistados/as evidenciam a importância do PRP para a formação inicial dos futuros docentes. Isto vai ao encontro das advertências propostas por Nóvoa (2006) ao enfatizar a necessidade de maiores cuidados com os licenciandos, pois, via de regra, já nos primeiros anos de carreira são colocados "nas piores escolas, com os piores horários e nas piores turmas" (NÓVOA, 2006, p.14), sem qualquer tipo de apoio ou suporte, o que tem um impacto direto na formação e, consequentemente, na atuação profissional.

Vale destacar também que, conforme narra o professor Nascimento (2019), o PRP propicia aos envolvidos o exercício da "transposição didática", ou seja, da necessária adequação para o espaçotempo escolar dos saberes epistêmicos produzidos pela ciência em suas respectivas áreas do saber.

Neste sentido, é importante destacar que a noção de transposição didática, em Chevallard (1991), caracteriza-se pelo processo de tornar didático o saber acadêmico para que ele possa ser estudado e apreendido com os/as estudantes na escola. Segundo o teórico, o processo de transposição didática seria realizado por uma instituição invisível, denominada por ele de 'noosfera', formada por pesquisadores acadêmicos, especialistas, professores/as, etc. que definirão quais conteúdos e como devem chegar à escola. No Brasil, essa instituição invisível mencionada pelo autor pode ser referenciada pela atuação do Ministério da Educação, das Secretarias Estaduais e Municipais de Educação, e das Universidades que juntos dialogam para a construção dos Referenciais Curriculares e, possibilitam a implementação de programas e projetos, tais como o PRP. 
No que tange à formação continuada, as narrativas dos/as professores/as preceptores/as, revelam que o PRP tem forte impacto, contribuindo não somente para a capacidade de formação de novos professores, mas também para a formação continuada dos professores já inseridos nas redes de educação básica de ensino.

Conforme desvelam as narrativas de nossos colaboradores/as, tal contribuição se efetiva, via de regra, pelas possibilidades de contato e aproximação com as Instituições de Ensino Superior, responsáveis pela formação inicial, mediada pelos saberes dos residentes. Como tal, abre-se a oportunidade para os professores preceptores/as se atualizarem e se reinserirem no movimento contínuo de formação. Essa percepção é enfatizada pelo professor preceptor, ao afirmar que "O PRP é importante primeiro porque que me faz estudar, estar em contato com a universidade. Saber que os professores têm que ser acima de tudo pesquisadores" [sic] (NASCIMENTO, 2019).

Correlato a essa temática, Tardif (2008) expõe que “[...] as fontes da formação profissional dos professores não se limitam à formação inicial na universidade; trata-se, no verdadeiro sentido do termo, de uma formação contínua e continuada que abrange toda a carreira docente" (TARDIF, 2008, p. 287).

Essa contribuição formativa também é bastante evidenciada nas narrativas de outra professora preceptora, tomando por referência o rompimento com a solidão na qual, geralmente, é pautado o trabalho docente na educação básica. Em suas palavras, o Programa Residência Pedagógica e a presença dos licenciandos/as residentes,

[...] além deles contribuírem para eu repensar minhas metodologias, minha própria relação com os alunos e o modelo de educação que eu gostaria de alcançar, me trouxe para essa dinamização de delegar funções, orientar e descentralizar essa solidão do professor nos seus planejamentos e nas salas de aulas que muitas vezes acontece [sic] (RICARDO, 2019).

No que tange à formação continuada de professores, Gatti (2008) destaca gargalos ao apontar que, no Brasil, a mesma assume caráter/feição de um programa compensatório e não propriamente de atualização e aprofundamentos em avanços do conhecimento. Segundo a referida autora, a formação continuada tem sido, via de regra, utilizada com a finalidade de suprir a má formação dos profissionais da educação, alterando assim seu propósito inicial de aprimoramento, avanço, renovação e inovação de conhecimentos nas mais variadas áreas do conhecimento.

Neste contexto, Lima (2018) destaca a fragmentação dos projetos curriculares, a frágil formação teórico-metodológica e a dicotomia entre teoria e prática como os pilares da 
fragilidade das políticas de formação inicial e continuada dos educadores no Brasil. O autor destaca, inclusive, que a formação docente ainda é arraigada em práticas formativas descontextualizadas da realidade social e escolar vigorante em grande parte do país, além da ausência de uma inserção crítica dos licenciandos/as no cotidiano escolar que permita a apropriação da cultura da docência ainda na fase de formação inicial:

[...] a compreensão das políticas e práticas de formação de educadores no Brasil passa pela discussão dos pressupostos políticos e epistemológicos que dão sustentação aos diferentes modelos de formação instituídos em nosso país nos diferentes tempos e espaços. O desvelamento desses pressupostos teórico-metodológicos e político-ideológicos podem tanto abrir caminhos para o desvelamento das políticas de educação e de formação de educadores, quanto contribuir no desenvolvimento de estratégias políticas e pedagógicas associadas à luta pela formação crítica dos educadores. (LIMA, 2018, p. 107).

$\mathrm{Na}$ vertente da formação crítica dos profissionais da educação, Nóvoa (1992) destaca os modelos utilizados na construção da educação continuada, uma vez que, na maioria dos casos, não tem conexão com a realidade vivenciada no cotidiano escolar e ocorrendo de modo a não proporcionar uma articulação teórico-metodológica rígida e eficaz.

Nesse sentido, conforme narrativas de nossos/as colaboradores/as entrevistados/as, o PRP propiciou contribuições significativas para o processo formativo, visto que o contato direto com os licenciandos/as residentes lhes propiciou uma efetiva reflexão acerca de seus processos de formação continuada, principalmente ao promover uma maior aproximação, direta ou indiretamente, com a instituição de formação inicial e com os saberes acadêmicos, propriamente ditos.

No que se refere à presença e atuação do residente e sua contribuição para o ensino de geografia na escola-campo em que atua, nota-se nas narrativas de nossos/as colaboradores/as certa ênfase ao destacar, quase sempre, o "frescor acadêmico" dos/as residentes, por estarem ainda em período de formação e mais conectados/as às questões que estão em voga na sociedade. Segundo suas narrativas, os/as residentes, ao levarem tal "frescor" para as escolas foram fundamentais para a atualização dos saberes escolares, por vezes "cristalizados".

Eu considero o PRP como um campo de experimentação. A gente está experimentando, testando, teorizando, praticando muitas coisas novas. [...] e por mais que a gente vem se atualizando eles [residentes] trazem esse novo frescor para a escola, fazendo que o ensino da geografia se torne mais rico [...][sic] (RICARDO, 2019). 
Outra questão enfatizada durante as entrevistas se refere às novas tecnologias e sua relação com a educação. Com o advento da globalização, as transformações nas sociedades, sobretudo, nas Tecnologias Digitais de Informação e Comunicação (TDICs) são evidentes. Seguindo este padrão, a educação não ficou alheia a essas mudanças e atualmente é impossível pensar a escola sem considerar que os dispositivos tecnológicos fazem parte de seu cotidiano.

Neste contexto, é comum nos relatos dos professores/as questões sobre as dificuldades em acompanhar os avanços tecnológicos recentes no campo da educação. Neste cenário, as narrativas de nossos/as professores/as preceptores/as revelam que os residentes contribuíram na superação de algumas dificuldades, facilitando aprendizagens acerca do uso desses aparatos tecnológicos na escola. Isso fica evidenciado na narrativa de uma das professoras preceptoras, que afirma:

Eu acho que eles [os residentes] me ajudaram principalmente na parte tecnológica, que eu tenho muita dificuldade. As pessoas da minha idade, a maioria, tem dificuldade e até certa resistência em mexer no computador, preparar aulas em Power Point, etc. Tenho dificuldades e nisso eles me ajudam muito, inclusive em, elaborar provas, etc. [sic] (BARROS, 2019).

Neste sentido, destacamos que os avanços tecnológicos chegam na educação não somente demandando novas práticas metodológicas que considerem os dispositivos de informática indispensáveis no processo de ensinoaprendizagem, como tende à completa informatização das pautas para o lançamento de conteúdos, frequência e notas. No Espírito Santo, por exemplo, toda rede estadual de ensino conta com o Sistema Estadual de Gestão Escolar (SEGES), assim como na Secretaria Municipal de Educação de Vitória, onde também está em vigor o Sistema de Gestão Escolar (SGE). Esses sistemas, informatizados, que são cada vez mais comuns, permitem maior integração da escola com a família, e possibilitam o fácil acesso ao desempenho dos estudantes. Entretanto, a adaptação dos/as docentes é um processo natural e gradual.

Desse modo, o que está sendo colocado em evidência é que o Programa Residência Pedagógica apresentou um grande potencial para a formação inicial e continuada de professores, por incentivar a troca de saberes entre os/as professores/as e os/as licenciandos/as. Além disso, como ganho secundário, notou-se a potencialidade do PRP em auxiliar os/as professores que já estão inseridos no processo educacional a se ambientarem na era da informática, além de colaborarem para o desenvolvimento de aulas mais dinâmicas e interativas elaboradas a partir da incorporação das novas TDICs. 


\section{O Programa Residência Pedagógica (PRP) na visão dos/as Residentes Pedagógicos}

Para a realização das entrevistas, delimitamos nosso universo de pesquisa seguindo as orientações e os pressupostos da história oral temática. Além das vozes dos três professores/as preceptores/as, também se constituíram como sujeitos de entrevista, seis licenciandos/as residentes. Como o PRP de Geografia estava presente em três escolas-campo, foram entrevistados dois residentes de cada instituição. Definimos ainda, que o critério para seleção dos/as residentes a serem entrevistados/as seria uma consulta aberta e seleção dos dois primeiros residentes que aderissem voluntariamente à proposta da pesquisa.

À exemplo dos procedimentos adotados para os/as professores/as preceptores/as, também para os licenciandos/as residentes, elaboramos um roteiro semiestruturado com questões que possibilitassem desvelar, entre outros aspectos, de que maneira o PRP contribuiu com a formação docente de cada um/a e as motivações que os/as levaram a participar do programa.

Assim, as entrevistas foram realizadas estimulando narrativas acerca das percepções dos/as residentes no que se refere à contribuição do Programa Residência Pedagógica para a formação de professores de Geografia. Para tanto, o roteiro semiestruturado, inicialmente, pautou-se em questões do tipo "Como o Programa PRP está contribuindo com a sua formação docente?” e “Avalie, de um modo geral sua participação no Programa Residência Pedagógica".

Muitas narrativas emergidas durante as entrevistas confluem para uma ilustração positiva acerca do PRP e sua relevância para a formação docente e o protagonismo dos/as licenciando/as, como a que destacamos na sequência:

Bom, essa vivência que eu tenho no Residência, duas vezes na semana, é
uma vivência que me possibilitou retirar o melhor e o pior de cada momento.
Eu tento captar aquilo que o professor fala que eu acho interessante,
exemplos, pois ele já tem mais experiência. Alguns exemplos que ele dá são
legais, a forma que ele conduz a aula e também a forma como meus colegas
residentes dão aula, porque eu aprendo com eles também. E muito. Eu estou
tentando fazer isso, vendo também os erros que, pelo menos pra mim são
erros, que eu não pretendo fazer e tentando filtrar tudo isso [sic]
(CORADINI, 2019).

Corroborando a ideia das oportunidades criadas no âmbito do Programa Residência Pedagógica a fim de permitir experiências mais práticas em detrimento dos conteúdos teóricos abordados na graduação, um/a residente destaca: 
Antes a gente ficava muito no campo teórico. O nosso currículo não nos dá muita oportunidade para entrar, realmente estar inserido na escola. A gente fica muito no campo teórico, romantizando muitas vezes a educação. Então aqui eu consigo associar toda a teoria que a gente aprendeu lá na Universidade com a prática aqui na escola básica [sic] (PINHEIRO, 2009).

Pelo prisma da prática docente, pode-se afirmar que o PRP oportunizou a experiência e despertou nos/as residentes maior confiança dentro de sala, conforme explicitado na narrativa de outro sujeito da pesquisa, “o Residência Pedagógica está contribuindo com minha formação de um modo que eu não me sinto mais despreparado para chegar em uma sala de aula e dar aula, principalmente na questão de segurança" [sic] (BASTOS, 2019).

A importância do Programa evidencia-se ainda mais na narrativa seguinte:

Talvez esse um ano e meio de residência tenha sido mais proveitoso do que todo o período da minha formação como professor que tive antes do Programa. Porque você ficar aqui lendo texto e fazendo trabalho é totalmente diferente do que você estar na realidade da escola, de você entender todo o contexto do que é a sala dos professores, o que é a escola, o que é a relação com o pedagogo, diretor, professor, alunos, pais de alunos. Isso só foi possível perceber com o Programa. Além de ter a oportunidade de ver se é realmente isso que eu quero para minha vida [sic] (CARNEIRO, 2019).

A partir desta narrativa, observamos que outro aspecto a ser destacado se refere à reflexão que é oportunizada pelo PRP acerca do futuro profissional ao qual deseja seguir, ou seja, o contato com o Programa auxilia o/a estudante de licenciatura a decidir se realmente quer seguir a carreira docente. Essa percepção é, também, visível na narrativa que segue:

Não quero dar aula. Pelas questões que a gente vê dentro da sala dos professores. Você entra na sala dos professores e é uma falação: "Aí que esse aluno não vai conseguir nada na vida". Eu sei que é muito trabalhoso ser professor, só que eles não param pra conversar com o aluno, entende? Para ver o que ele está passando, porque que ele é daquele jeito. Mas foram esses motivos que me fizeram desanimar de querer dar aula [sic] (COSTA, 2019).

Destacamos, portanto, que o Programa, além de emergir como uma sala de aula experimental que permite o aprendizado a partir da prática, é também um laboratório em que os/as residentes, por meio da experiência vivenciada no cotidiano escolar, avaliam se o caminho da docência é aquele pelo qual desejam trilhar suas histórias e sua profissão.

Quando perguntados sobre a principal motivação para participação no PRP, grande parte dos/as residentes entrevistados/as assinalou a possibilidade de adquirir experiência e, também, a bolsa auxílio. 
Um dos sujeitos da pesquisa, ao refletir sobre os motivos de seu envolvimento com o Programa, sinaliza, também a importância e validade de Programas como o Residência Pedagógica para a formação dos profissionais da educação.

Primeiramente a oportunidade de estar atuando como professor. A gente vê muito a teoria na universidade e nos cursos de licenciatura. Até eu ir para o Residência Pedagógica, não tinha tido a prática de entrar na sala de aula realmente. E, no curso de licenciatura em Geografia, a primeira oportunidade de ir para a sala de aula, pelo menos no currículo antigo, era em Estágio II. $\mathrm{E}$, isso prejudica o que a gente espera do curso [sic] (CARNEIRO, 2019).

Em sua narrativa, o/a residente aborda a questão da experiência, fazendo uma crítica à própria estruturação do currículo do curso de licenciatura em Geografia que, segundo ele, possui baixa carga horária de prática docente. Esse gargalo, não possibilita ao licenciando/a ter a experiência completa do cotidiano escolar e da rotina de professores/as, que poderia envolver o planejar e o ministrar aulas, elaborar e corrigir atividades avaliativas, além de (con)viver com os diferentes sujeitos da escola.

De acordo com Veiga (2009) e Tardif (2009), a prática e a teoria precisam andar lado a lado na formação de professores, num sentido horizontal e não vertical. Conforme esse princípio, o educador precisa compreender que a sua atividade pedagógica se estende entre as teorias e práticas, de maneira que surge a partir da prática e se fundamenta por meio da teoria.

Acerca da bolsa auxílio, concedida pelo PRP, muitos/as licenciandos/as destacam que emerge como um incentivador muito importante para a participação e continuidade no Programa, uma vez que muitos/as estudantes só residem na Região Metropolitana da Grande Vitória (RMGV), pelo fato de estarem realizando a graduação, e em decorrência disso, necessitam, em muitos casos, das bolsas e auxílios para se manterem no curso.

A princípio o que me motivou foi a questão do dinheiro. Porque o Programa Residência dá essa abertura para que você tenha uma bolsa na universidade ou em outro projeto, de maneira cumulativa com a bolsa da residência. Então, isso me agradou, porque eu já tinha um estágio e através do Programa eu pude estar na Residência e juntou as minhas duas bolsas e eu me mantenho. E, então a princípio foi questão financeira, para me manter aqui em Vitória [sic] (CORADINI, 2019).

Este fato referente à possibilidade de acúmulo de bolsa, mencionado na narrativa da residente, pode ser caracterizado como um dos grandes diferenciais do PRP, tendo em vista que o/a residente que necessita de maiores recursos financeiros, tem a possibilidade de encontrar outros meios de remuneração. 
Não obstante, outro fato que se destacou nas narrativas a respeito da motivação em participar do PRP se refere ao cumprimento da carga horária complementar obrigatória para todos os cursos de graduação da $\mathrm{UFES}^{5}$, conforme destaca outro sujeito da pesquisa: "sendo muito sincera, a faculdade exige que a gente faça algumas horas complementares para poder concluir a graduação e esse foi um dos principais motivos que me motivaram a estar aqui no Programa Residência Pedagógica” [sic] (ZANDONADI, 2019).

\section{Experiment(ações) no ensino de Geografia no âmbito do Programa Residência Pedagógica de Geografia (UFES)}

Nesta seção, destacamos algumas metodologias de ensinoaprendizagem e projetos de ensino implementados durante a vigência do PRP nas escolas-campos e que se constituíram em saberes/fazeres dos/as professores/as e licenciandos/as residentes entrevistados. Assim, buscamos seguir as orientações de Borges e Bitte (2018), ao enfatizarem a importância de se registrar e socializar as vivências, metodologias e projetos, etc. que ocorrem no cotidiano escolar para que tais experiências não fiquem confinadas aos segredos da sala de aula:

[...] os professores são tomados como os produtores de seus próprios saberes, quando no exercício de sua função docente, desenvolvem truques, esquemas e estratagemas que lhes possibilitem superar as mais diversas situações, que, embora corriqueiras são dinâmicas. Essas técnicas, truques e estratagemas desenvolvidos pelo docente na "solidão" de si com suas "repletas" salas de aula são saberes que lhe são particulares e, se não socializados, permanecem em segredo (BORGES, BITTE, 2018, p. 42).

Dentre as várias metodologias de ensinoaprendizagem realizadas e narradas por nossos/as entrevistados/as, destacamos a atividade denominada de "Censo ABL 2019", realizada na escola-campo de Vitória. Ainda, merecem destaques as atividades "Maquete do relevo do Brasil", implementada na escola-campo-Serra, bem como o projeto "Identidade e identificação”, desenvolvido na escola-campo Vila Velha. Vejamos a seguir:

Censo ABL 2019

Essa proposta de ensino, realizada na escola-campo de Vitória (Escola Municipal de Ensino Fundamental Aristóbulo Barbosa Leão - ABL), emergiu da necessidade de se

\footnotetext{
${ }^{5}$ Segundo as Diretrizes Curriculares Nacionais para a Formação de Professores - Resolução 02/2015 CNE/CP -, todo curso de licenciatura, deve prever uma carga horária mínima de 200 horas para atividades teórico-práticas complementares.
} 
trabalhar os conteúdos relativos à geografia da população com a turma do sétimo ano matutino. Como no ano seguinte (2020) seria realizado o Censo Demográfico brasileiro, pelo Instituto Brasileiro de Geografia e Estatística (IBGE), pensou-se em reproduzir essa pesquisa numa escala menor. No período matutino, a escola atende quatro turmas, no Ensino Fundamental II, além da turma de sétimo ano, que realizou a pesquisa. Assim, os/as residentes e a professora preceptora separaram a turma em quatro grupos, de modo que cada grupo ficasse responsável por entrevistar os integrantes de uma das demais quatro turmas. Dentro dos respectivos grupos, os/as residentes também definiram quais componentes ficariam responsáveis por entrevistar cada estudante da turma a ser entrevistada, garantindo, assim, que ninguém ficasse sem participar da pesquisa.

Para a coleta de dados, utilizou-se de um questionário simples, que buscou focar nas questões relacionadas ao número de filhos das avós, maternas e paternas e das mães, a fim de perceber as alterações relacionadas às taxas de fecundidade e natalidade. Além disso, buscouse realizar um questionário que atendesse aos gostos dos/as estudantes, perguntando, por exemplo, qual o gosto musical favorito, perguntas relacionadas à merenda escolar, religião e vários outros.

A culminância do projeto foi a elaboração de cartazes expostos no pátio da escola, apresentando em gráficos os resultados das pesquisas. Os resultados também foram expostos no dia de um dos mais tradicionais eventos da instituição: o Sarau Geográfico, que abordaremos em seguida.

\section{Maquete do relevo do Brasil}

Essa metodologia teve como principal objetivo mostrar aos discentes da educação básica, as principais características físicas das regiões brasileiras (relevo, hidrografia, clima, vegetação). A partir da leitura de climogramas, em um exercício de fixação em sala de aula, surgiu a necessidade de ensinar aos/às estudantes como é formado o clima de cada região do Brasil, considerando o clima como a síntese das características físicas de determinado local.

Os/As discentes primeiramente estudaram as peculiaridades de cada região do Brasil no que tange aos aspectos físicos e, em seguida, iniciou-se o processo de construção das maquetes, utilizando caixas de ovos e papelão como base. O relevo do Brasil foi moldado com papel machê e pintado com tinta guache. 


\section{Projeto Identidade e Identificação}

Para o desenvolvimento desta atividade, realizou-se junto com os/as estudantes da escola campo, discussões baseadas no livro didático, abordando conceitos geográficos, em especial os de lugar e espaço. Em seguida, foi solicitado aos/às estudantes que realizassem uma entrevista com alguma pessoa que fosse residente, há bastante tempo, no bairro Ilha do Ayres, em Vila Velha-ES, local onde se situa a unidade escolar. Para tanto, o/a entrevistado/a poderia ser, inclusive, da própria família do estudante. A última atividade foi uma redação, solicitada ao corpo discente, abordando os aspectos que ele mais gostava ou desgostava no bairro. Ao final, foi montado um painel com alguns trechos das redações.

Em consonância com a proposta central do Subprojeto Geografia do Programa Residência Pedagógica, as três escolas parceiras e todos os sujeitos diretamente envolvidos, buscaram conduzir as atividades pautadas em princípios da Pedagogia de Projetos, ou seja, buscando envolver as classes de aulas, onde os residentes e preceptores atuariam, em atividades proveitosas, cujos propósitos seriam colocar os/as estudantes como protagonistas na construção do seu conhecimento. Assim, as propostas de ação desenvolvidas ao longo do período de realização do PRP tiveram sua culminância na realização do chamado Sarau Geográfico.

O Sarau Geográfico pode ser considerado como um projeto guarda-chuva, constituído por vários subprojetos de ensino, desenvolvidos ao longo do ano letivo, tendo por eixo um tema gerador, relacionado ao ensino de Geografia. O Sarau Geográfico visa trabalhar a Geografia por meio de outras linguagens, como a poesia e o teatro, por exemplo. A culminância do Sarau Geográfico se efetiva, com a definição de uma data específica para apresentação e socialização, para a comunidade escolar, dos vários subprojetos desenvolvidos durante o ano letivo, além de atividades culturais.

Na escola-campo de Vitória, o Sarau Geográfico aconteceu em 28 de setembro de 2019, tendo por tema, “Ontem e Hoje: Geografando os saberes”. Nesta edição, o evento teve como objetivo abordar temáticas sob a perspectiva da geografia-histórica, discutindo acontecimentos marcantes ao longo dos tempos. Já na escola-campo de Vila Velha, o Sarau geográfico ocorreu em 9 de novembro de 2019 e a temática central foi "No espaço geográfico que caminha a vida”. Na escola-campo de Serra, por sua vez, o Sarau Geográfico ocorreu em 29 de novembro de 2019, com a temática "Água e sustentabilidade”. 


\section{Considerações Finais}

Diante das discussões abordadas, faz-se necessário enfatizarmos alguns aspectos acerca do Programa Residência Pedagógica. Em primeiro lugar, a constatação de sua importância para com a formação de novos professores e professoras, desvelada em várias oportunidades nas narrativas dos/as sujeitos/as entrevistados/as, em especial por aqueles/as de fato em formação: os/as licenciandos/as - no papel de residentes.

É opinião comum, compartilhada por todos os/as sujeitos/as da pesquisa, dentro do grupo pesquisado, que os currículos dos cursos de graduação, nas mais diversas licenciaturas, possuem carga horária na disciplina de Estágio Supervisionado insuficiente para imersão nos mais diversos e controversos contextos e espaçostempos da escola. Desta maneira o PRP se configura como uma oportunidade de complementar a experiência dos Estágios Obrigatórios, além de possibilitar uma série de outras vivências - não somente positivas - que provavelmente os/as licenciandos só teriam exercendo a docência.

Além dos saberes construídos e compartilhados no âmbito do Programa, destaca-se sua importância enquanto política de permanência nas Universidades, uma vez que oferece uma bolsa-auxílio, apresenta carga horária acessível e não impõe, burocraticamente, a exclusividade de vinculação ao Programa.

Em segundo lugar, as narrativas dos professores preceptores desvelam, implícita e explicitamente a importância do Programa para a formação (inicial e continuada) dos/as professores/as preceptores/as que, por meio do contato com os/as residentes constroem conhecimentos, repensam seus planejamentos e reestruturam suas aulas. Essa constatação é muito interessante no sentido de asseverar o alcance de um dos objetivos explícitos do Residência Pedagógica, que o Programa, por meio de suas ações, propiciasse o estreitamento da relação entre as Escolas e a Universidade.

A pesquisa revelou ainda que a experiência do Programa Residência Pedagógica cria um ambiente de ensinoaprendizagem em redes, raízes, galhos, rizomas (DELEUZE e GUATTARI, 1995), em que se possibilita aos/às residentes o contato com a docência por meio da prática, aos/às preceptores/as um momento também de aprendizagem e reformulação de seus saberes e fazeres docentes e aos/às estudantes das escolas-campo o contato com os conteúdos da disciplina por meio de metodologias de ensino dinâmicas, contextualizadas e envolventes. 


\section{REFERÊNCIAS}

BARROS, Luciane Sarmento Firme Soneghet. Depoimento. [set. 2019]. Entrevistador: Lucas de Souza Leite. Vitória - ES, 2019.

BOM MEIHY, José Carlos Sebe. Manual de história oral. São Paulo: Loyola, 1996.

BORGES, Vilmar José. Modos de realizar estágio curricular supervisionado em geografia: vozes de professores supervisores e professores parceiros na Região Sudeste (Brasil) / Vilmar José Borges - 2012. 250 f. Tese (Doutorado em Educação Escolar) Universidade Estadual Paulista, Faculdade de Ciências e Letras, Campus de Araraquara. São Paulo, 2012.

BORGES, V. J. e BITTE, R. C. F. Estágio Curricular Supervisionado: identidade e saberes docentes. Educação em Perspectiva. Viçosa, v. 9, n. 1, p. 30-47, 2018.

BRASIL. CAPES. Edital 6: Chamada Pública para apresentação de propostas no âmbito do Programa de Residência Pedagógica. 2018. Brasília: Ministério da Educação 2018.

. CAPES. Portaria n. ${ }^{\circ}$ 45, 12/03/2018. Brasília: Ministério da Educação 2018.

. CAPES. Portaria n. 38, 28/09/2018. Brasília: Ministério da Educação 2018.

. CAPES. Portaria n. 35, 28/09/2018. Brasília: Ministério da Educação 2018.

Parecer CNE/CP 009/2001 de 08.05.2001, do Conselho Nacional de Educação. Diretrizes Curriculares Nacionais para a Formação de Professores da Educação Básica, em nível superior, curso de Licenciatura, de Graduação plena. Disponível em <http://portal.mec.gov.br/cne/arquivos/pdf/009.pdf>. Acesso em 02.02.2009.

Parecer CNE/CP 21/2001, de 06.08.2001, do Conselho Nacional de Educação. Dispõe sobre a duração e carga horária dos cursos de Formação de Professores da Educação Básica, em nível superior, curso de Licenciatura, de Graduação plena. Disponível em <http://portal.mec.gov.br/cne/arquivos/pdf/021.pdf>. Acesso em 02.02.2009.

Parecer CNE/CP 28/2001 de 02.10.2001, do Conselho Nacional de Educação. Dá nova redação ao Parecer CNE/CP 21/2001, que estabelece a duração e a carga horária dos cursos de Formação de Professores da Educação Básica, em nível superior, curso de Licenciatura, de Graduação plena. Disponível em <http://portal.mec.gov.br/cne/arquivos/pdf/028.pdf>. Acesso em 02.02.2009.

Parecer CNE/CP 27/2001, de 02.10.2001, do Conselho Nacional de Educação. Dá nova redação ao Parecer CNE/CP 9/2001, que dispõe sobre as Diretrizes Curriculares Nacionais para a Formação de Professores da Educação Básica, em Cursos de Nível Superior. Disponível em <http://portal.mec.gov.br/cne/arquivos/pdf/027.pdf>. Acesso em 02.02.2009

Resolução 01/2002, de 18.02.2002, do Conselho Nacional de Educação. Institui Diretrizes Curriculares Nacionais para a Formação de Professores da Educação Básica, em 
nível superior, curso de Licenciatura, de Graduação plena. Disponível em <http://portal.mec.gov.br/cne/arquivos/pdf/rcp01_02.pdf>. Acesso em 02.02.2009.

Resolução 02/2002, de 19.02.2002, do Conselho Nacional de Educação. Institui a duração e a carga horária dos cursos de Licenciatura, de Graduação plena, de formação de professores da Educação Básica em nível superior. Disponível em http://portal.mec.gov.br/cne/arquivos/pdf/CP022002.pdf. Acesso em 02.02.2009.

Resolução CNE/CP no 02, de 01 de julho de 2015. Diretrizes Curriculares Nacionais para a formação inicial em nível superior e para a formação continuada. Disponível: <http://portal.mec.gov.br/index.php?option=com_docman\& view=download\&alias=17719-res-cne-cp-002-03072015\&category_slug=julho-2015pdf\&Itemid=30192>

CARNEIRO. Rômulo Marconi. Depoimento. [set. 2019]. Entrevistador: Marcone Henrique de Freitas. Vila Velha - ES, 2019.

CHEVALlARD, Yves. La Transposition Didactique: Du Savoir Savant au Savoir Ensigné. Grenoble, La pensée Sauvage. 1991.

CORADINI, Natália Barbosa. Depoimento [set. 2019]. Entrevistador: Lucas de Souza Leite. Serra - ES, 2019.

COSTA, Thaís Barbosa. Depoimento. [set. 2019]. Entrevistador: Marcone Henrique de Freitas. Vitória - ES, 2019.

DELEUZE. Gilles; GUATTARI. Félix. Mil Platôs (Capitalismo e Esquizofrenia) Vol. 1 Editora 34, $1^{a}$ Ed. (1995) (Esgotado) Tradução de Aurélio Guerra Neto e Célia Pinto Costa .

FARIA, Juliana Batista; PEREIRA, Júlio Emílio Diniz. Residência Pedagógica: afinal, o que é isso? Rev. de Educação Pública. V.28, n. ${ }^{\circ}$ 68, p.333-356, Agosto, 2019. Disponível em: https://www.researchgate.net/publication/333226811_Residencia_pedagogica_afinal_o_que e_isso. Acesso em 19 de Set. de 2019.

GATTI, Bernadete Angelina. Análise das políticas públicas para formação continuada no Brasil, na última década. Revista Brasileira de Educação, v. 13 n. 37 jan./abr. 2008.

ICHIKAWA, Elisa Yoshie; SANTOS, Lucy Woellner dos. Vozes da História: Contribuições da História Oral à Pesquisa Organizacional. In: Encontro Nacional da Associação dos Programas de Pós-Graduação em Administração., 27, 2003, Atibaia. Anais... Atibaia: ANPAD, 2003. 1 CD.

LIMA, Elmo de Souza. A formação continuada como espaço de reorientação curricular: reflexões teórico-metodológicas. Revista Educação e Cultura Contemporânea, v.15, n.41, 2018.

NASCIMENTO, Carlos Alberto da Silva. Depoimento. [set. 2019]. Entrevistador: Marcone Henrique de Freitas. Serra - ES, 2019. 
NÓVOA, António. Formação contínua de professores: realidade e perspectivas. Aveiro: Universidade de Aveiro, 1992.

NÓVOA, Antônio. Desafios do trabalho do professor no mundo contemporâneo. Nada substitui o bom professor. Palestra proferida no Sindicato dos Professores de São Paulo, São Paulo, 2006. Disponível em:

<http://www.sinprosp.org.br/arquivos/novoa/livreto_novoa.pdf $>$. Acesso em: 03 nov. 2019.

NÓVOA, António. Entre a formação e a profissão: ensaio sobre o modo como nos tornamos professores. Currículo sem Fronteiras, v. 19, n. 1, p. 198-208, jan./abr. 2019.

PIMENTA, Selma Garrido. O Estágio na Formação de Professores. Unidade Teoria e Prática? 9. ed. São Paulo: Cortez, 2010.

RICARDO, Thainá Guimarães. Depoimento. [set. 2019]. Entrevistador: Marcone Henrique de Freitas. Vila Velha - ES, 2019.

SANTOS, Artur Bastos. Depoimento. [set. 2019]. Entrevistador: Marcone Henrique de Freitas. Vila Velha - ES, 2019.

SANTOS, Karolayne Pinheiro dos. Depoimento. [set. 2019]. Entrevistador: Lucas de Souza Leite. Vitória - ES, 2019.

TARDIF, Maurice. O que é saber da experiência no ensino? In: ENS, Romilda T.;

VOSGERAU, Dilmeri S. R.; BEHRENS, Marilda A. (Orgs.). Trabalho do professor e saberes docentes. Curitiba: Champagnat, 2009. p. 25-39.

VASQUEZ, Adolfo Sánchez. Filosofia da práxis. 2. ed. Rio de Janeiro: Paz e Terra, 1977. VEIGA, Ilma Passos Alencastro. A aventura de formar professores. Campinas: Papirus, 2009. Fontes Orais

ZANDONADI, Cecília Uliana. Depoimento. [set. 2019]. Entrevistador: Lucas de Souza Leite. Vitória - ES, 2019.

\section{SOBRE OS AUTORES:}

\section{Vilmar José Borges}

Doutor em Educação Escolar pela UNESP (Araraquara-SP), Brasil. Professor permanente do Programa de Pós-Graduação Mestrado Profissional em Educação (PPGMPE) da Universidade Federal do Espírito Santo (UFES); Pesquisador e líder do grupo de pesquisa (CNPq) Narrativas, memórias, saberes e fazeres de professores de Geografia e de História da Educação Básica (UFES). E-mail: vilmar.geo@gmail.com

(iD http://orcid.org/0000-0002-0846-0621 


\section{Lucas de Souza Leite}

Mestrando em Educação na Universidade Federal do Espírito Santo (UFES), Brasil; Programa de Pós-Graduação em Educação (PPGE); Pesquisador do grupo de pesquisa (CNPq) Políticas, Gestão e Inclusão Escolar (UFES). E-mail: lucas.souzaleite@outlook.com

(iD https://orcid.org/0000-0002-0825-5046

\section{Marcone Henrique de Freitas}

Mestrando em Geografia na Universidade Federal do Espírito Santo (UFES), Brasil; Programa de Pós-Graduação em Geografia (PPGG); Pesquisador do laboratório de Geografia da Saúde (UFES). E-mail: marcone.h.freitas@gmail.com

iD https://orcid.org/0000-0002-6346-4641

Recebido em: 02 de julho de 2020 Aprovado em: 17 de novembro de 2020 Publicado em: 01 de dezembro de 2020 